Check for updates

Cite this: Chem. Sci., 2019, 10, 1029

๑ All publication charges for this article have been paid for by the Royal Society of Chemistry

Received 21st September 2018 Accepted 9th November 2018

DOI: $10.1039 / \mathrm{c} 8 \mathrm{sc} 04216 \mathrm{k}$

rsc.li/chemical-science

\section{Defying strain in the synthesis of an electroactive bilayer helicene $\uparrow$}

\author{
Margarita Milton, $\ddagger^{a}$ Nathaniel J. Schuster, $\star^{\star a}$ Daniel W. Paley, ${ }^{b}$ \\ Raúl Hernández Sánchez, (D) C Fay Ng, ${ }^{a}$ Michael L. Steigerwald ${ }^{\star a}$ \\ and Colin Nuckolls (D) *a
}

\begin{abstract}
We report the synthesis of a bilayer chiral nanographene incorporating a [7]helicene scaffold and two perylene-diimide (PDI) subunits. Twofold visible-light-induced oxidative cyclization of a phenanthrene framework selects for the desired PDI-helicene, despite the immense strain that distinguishes this helicene from two other accessible isomers. This strain arises from the extensive intramolecular overlap of the PDI subunits, which precludes racemization, even at elevated temperatures. Relative to a smaller homologue, this PDI-helicene exhibits amplified electronic circular dichroism. It also readily and reversibly accepts four electrons electrochemically. Modifications to the core phenanthrene subunit change the fluorescence and electrochemistry of the PDI-helicene without significantly impacting its electronic circular dichroism or UV-visible absorbance.
\end{abstract}

\section{Introduction}

This study concerns the regioselective synthesis and characterization of the newest and most highly strained perylene3,4,9,10-tetracarboxylic-diimide (PDI) helicene. In general, interactions between $\pi$-surfaces account for a variety of interesting electronic, optical, and magnetic phenomena. For instance, $\pi$-to- $\pi$ overlap promotes charge transport within organic semiconductors, ${ }^{1,2}$ a key consideration in the design of organic electronic and optoelectronic devices. ${ }^{3,4} \pi$-Extension of the termini of helicenes - helices of fused aromatic subunits surrounding a nonintersecting stereogenic axis - provides chiral nanographenes with considerable intramolecular $\pi$-to- $\pi$ overlap (Fig. 1a). Such chiral nanographenes may exhibit very large circular dichroism, ${ }^{5-7}$ circularly polarized luminescence, ${ }^{8,9}$ non-linear optical properties, ${ }^{10,11}$ and chiral-induced spin selectivity. ${ }^{12}$

The synthesis of helicenes, especially those with extensively eclipsed $\pi$-surfaces, hinges on the strategic accumulation of strain. ${ }^{13-15}$ Some synthetic complications can be avoided by attaching bulky polyaromatics after forming the helicene core. ${ }^{16}$ For other approaches, the possibility of unwanted cyclizations

\footnotetext{
${ }^{a}$ Department of Chemistry, Columbia University, New York, New York 10027, USA. E-mail:njs2154@columbia.edu; mls2064@columbia.edu; cn37@columbia.edu ${ }^{b}$ Columbia Nano Initiative, Columbia University, New York, New York 10027, USA ${ }^{c}$ Department of Chemistry, University of Pittsburgh, Pittsburgh, Pennsylvania 15260, USA

$\dagger$ Electronic supplementary information (ESI) available. CCDC 1864289 and 1864290. For ESI and crystallographic data in CIF or other electronic format see DOI: $10.1039 / \mathrm{c} 8 \mathrm{sc} 04216 \mathrm{k}$

\$ M. M. and N. J. S. contributed equally.
}

and attenuated reactivity must be considered. ${ }^{17-24}$ Clear synthetic guidelines exist for the preparation of helicenes via the oxidative photocyclization of stilbene-like scaffolds incorporating phenylene and naphthylene subunits. ${ }^{25}$ However, ensuring the exclusive formation of helicenes from the oxidative photocyclization of phenanthrene-based substrates remains difficult, ${ }^{26,27}$ especially when both twisted and planar (or nearly planar) polyaromatic products can be formed..$^{28}$

Here we disclose the synthesis of a $\pi$-extended [7]helicene via the regioselective visible-light-induced oxidative fusion of phenanthrene with two PDI subunits. This phenanthryl-linked PDI-dimer helicene (PPDH, Fig. 1b) belongs to an emerging class of chiral, shape-persistent, PDI-based materials prepared by intramolecular oxidative photocyclizations. ${ }^{29-31}$ Extensive intramolecular overlap of the $\pi$-surface distinguishes PPDH from its PDI-dimer helicene predecessors and the vast majority of $\pi$-extended helicenes. ${ }^{32-41}$ The strain attendant on this overlap disfavors the exclusive synthesis of PPDH near room temperature: the undesired [5]helicene isomer (5PPD, Fig. 1b) also forms. Simply raising the reaction temperature gives nearexclusive production of PPDH. This regioselectivity belies the disparity in strain between PPDH, 5PPD, and their planar isomer (PPPD, Fig. 1b). Single-crystal X-ray diffraction (SCXRD) of PPDH confirmed extensive intramolecular overlap of the $\pi$-surface, which contorts to mitigate intramolecular PDI-to-PDI contact. PPDH exhibits large electronic circular dichroism (ECD) in the visible range, especially relative to a smaller helical homologue, and readily accepts up to four electrons electrochemically. Finally, the fluorescence and electrochemistry of PPDH can be tuned by changing the substituents on its phenanthrene core. 

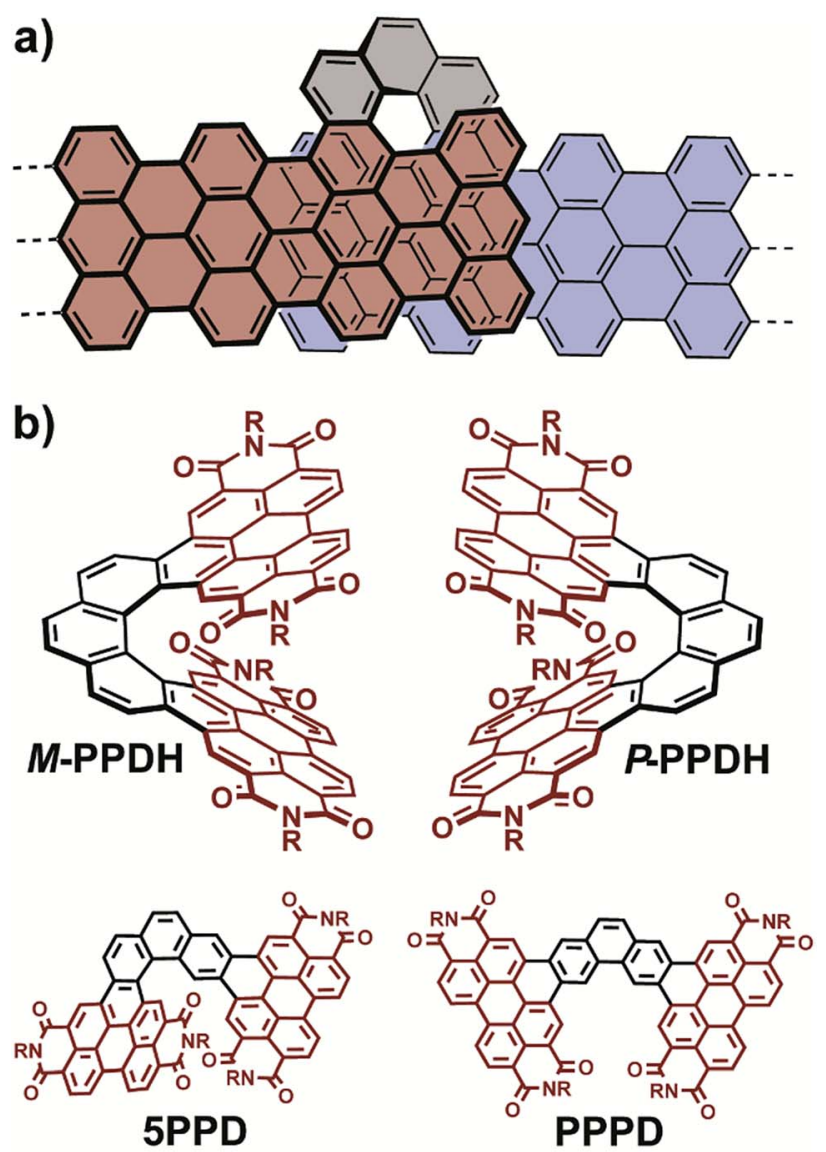

Fig. 1 (a) The fusion of two armchair nanographenes with phenanthrene provides a $\pi$-extended bilayer helicene. (b) Fusion with two PDI subunits via oxidative photocyclization at elevated temperatures overwhelmingly favors the formation of PPDH over its isomers, 5PPD and PPPD.

\section{Results and discussion}

Scheme 1 depicts our synthesis of PPDH. Intramolecular oxidative photocyclizations have been used to synthesize several helicenes from aryl-linked PDI-oligomers. ${ }^{\mathbf{4 2 , 4 3}}$ Acenes, in particular, fuse preferentially at the more sterically hindered peri-position under these reaction conditions, ${ }^{29-31,44}$ whereas oxidative photocyclizations onto 3,6-disubstituted phenanthrene (such as PPD in Scheme 1) may occur at any combination of the adjacent positions. We found that visible-light-induced oxidative cyclization of PPD at $110{ }^{\circ} \mathrm{C}$ formed PPDH almost exclusively (entry 3, Table 1 ). Repeating the oxidative photocyclization of PPD at $70{ }^{\circ} \mathrm{C}$ lowered the regioselectivity for PPDH: a 9 : 1 mixture of PPDH and 5PPD, respectively, resulted. A reaction temperature of $30{ }^{\circ} \mathrm{C}$ further decreased this ratio of PPDH-to-5PPD to $7: 3$. We never detected PPPD, no matter the reaction temperature. This absence of sterically unencumbered PPPD and the modest yields of 5PPD underscore a strong electronic preference for PPDH under these reaction conditions. Substituting two pentoxy substituents onto the phenanthrene linker does not alter this preference: these pentoxy substituents slowed the oxidative photocyclization of PPD (entry 4, Table 1), but did not dramatically alter the yield.

The strain energies of 5PPD, PPDH, and PPPD have no bearing on the regioselectivity observed for the twofold oxidative photocyclization of PPD. The DFT-optimized (B3LYP/6$31 \mathrm{G}^{* *}$ ) structures of 5PPD and PPDH are more strained (by 11 and $21 \mathrm{kcal} \mathrm{mol}^{-1}$, respectively) than PPPD (see Section VII of the ESI $\uparrow$ for the calculation details). Despite this strain, PPDH does not rearrange or decompose otherwise under ambient conditions, enabling the resolution of its left- $(M)$ and righthanded $(P)$ helices via chiral HPLC (Fig. S1†). The obvious rigidity of this PDI-helicene precludes inversion: optically pure PPDH heated in diphenyl ether at $250{ }^{\circ} \mathrm{C}$ under air for one hour showed neither racemization nor decomposition by HPLC (Fig. S2 $\dagger$ ). This stability contrasts with the relative lability of [7] helicene alone, which racemizes completely in solution in just over $3 \mathrm{~h}$ at $\sim 257^{\circ} \mathrm{C} .{ }^{45}$

Fig. 2a displays the ECD spectra of the resolved enantiomers of PPDH and its bis(pentoxy) analogue, PPDH-OPe (entry 4, Table 1). They exhibit many Cotton effects across the UV-visible range. The largest transitions of PPDH manifest as a bisignate pair centered at $\sim 360 \mathrm{~nm}:|\Delta \varepsilon|$ of $134 \mathrm{M}^{-1} \mathrm{~cm}^{-1}$ at $344 \mathrm{~nm}$ and $214 \mathrm{M}^{-1} \mathrm{~cm}^{-1}$ at $396 \mathrm{~nm}$. Naphthyl-linked PDI-dimer helicene (NPDH; see the inset of Fig. 2a) - the [6]helicene homologue of PPDH - shares this feature, albeit its corresponding Cotton effects are diminished: $|\Delta \varepsilon|$ of $41 \mathrm{M}^{-1} \mathrm{~cm}^{-1}$ at $355 \mathrm{~nm}$ and $56 \mathrm{M}^{-1} \mathrm{~cm}^{-1}$ at $401 \mathrm{~nm}$ (Fig. 2a). This strong enhancement in ECD from NPDH to PPDH deviates from the trend observed for the most intense bisignate pair shared by the carbohelicenes. Specifically, lengthening the carbohelicenes (e.g., [6]helicene to [7]helicene) has little effect on the intensity of the longer

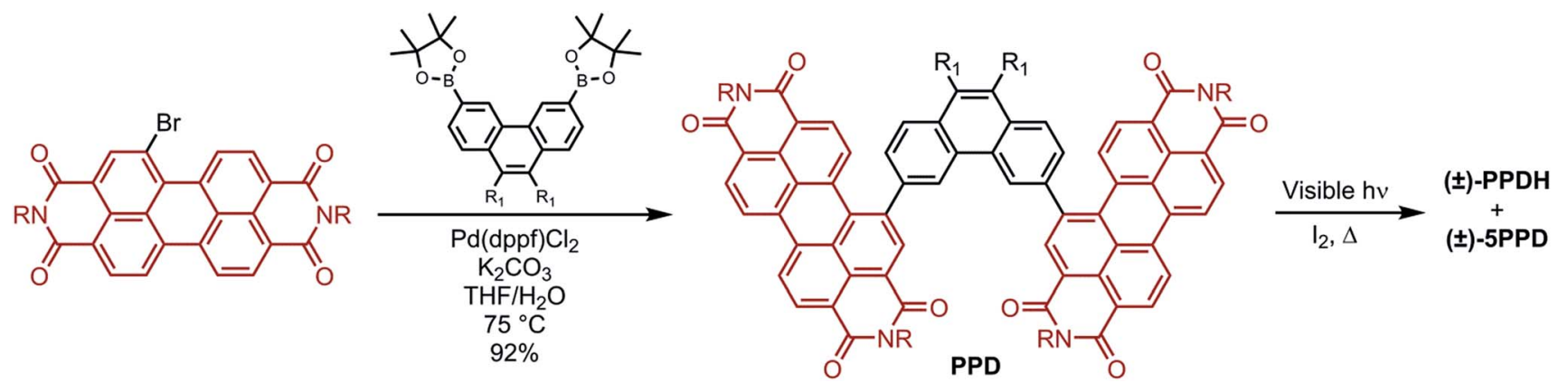

Scheme 1 Two-step synthesis of PPDH from brominated PDI $\left[\mathrm{R}=\mathrm{CH}\left(\mathrm{C}_{5} \mathrm{H}_{11}\right)_{2}\right]$. 
Table 1 Optimization of the twofold oxidative photocyclization of $\mathrm{PPD}^{a}$

\begin{tabular}{lllllll}
\hline Entry & $\mathrm{R}_{1}$ & $T\left({ }^{\circ} \mathrm{C}\right)$ & Solvent & Time $(\mathrm{h})$ & PPDH : 5PPD & Isolated yield of PPDH (\%) \\
\hline 1 & $\mathrm{H}$ & 30 & $\mathrm{PhH}$ & 24 & $70: 30$ & 63 \\
2 & 70 & $\mathrm{PhH}$ & 24 & $91: 9$ & 83 \\
3 & $\mathrm{H}$ & $\mathrm{PhCl}$ & 24 & $>95:<5$ & 91 \\
4 & $\mathrm{H}$ & $\mathrm{PhH}$ & 76 & $-^{c}$ & $88^{d}$
\end{tabular}

${ }^{a}$ The solutions of PPD $(0.2 \mathrm{mM})$ and iodine $(1.3 \mathrm{mM})$ were irradiated with two $55 \mathrm{~W}$ compact fluorescent lamps. Only a silica plug was necessary to remove 5PPD from PPDH. See the ESI for additional details. ${ }^{b}$ Determined by ${ }^{1} \mathrm{H}$ NMR of the product mixture. ${ }^{c}$ 5PPD was not observed, perhaps due to decomposition. ${ }^{d}$ Reaction did not go to completion; the remainder consisted of mono-cyclized intermediate and decomposition byproduct.

wavelength Cotton effect of this pair, which plateaus at $\sim 260 \mathrm{M}^{-1} \mathrm{~cm}^{-1} \cdot \mathbf{. 6}^{46}$

Chiral oligomers often exhibit ECD whose intensity scales linearly (or nearly linearly) with UV-visible absorbance; ${ }^{23,47}$
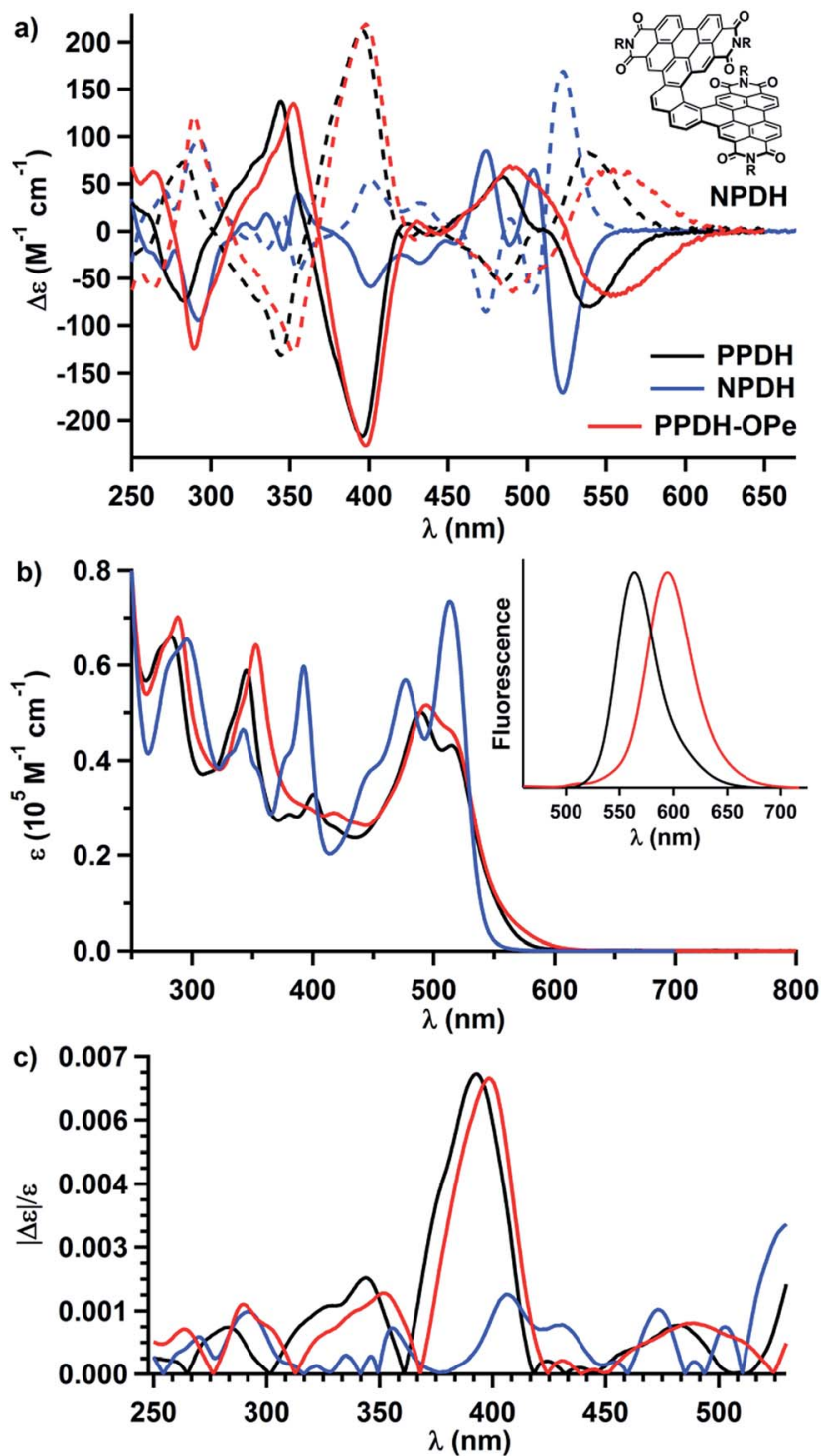

Fig. 2 (a) ECD, (b) UV-visible absorbance, and (c) $g$-factors of PPDH, $\mathrm{PPDH}-\mathrm{OPe}$, and NPDH in THF (10 $\mu \mathrm{M}, 1 \mathrm{~cm}$ path length). (Inset of b) Normalized fluorescence intensities of PPDH and PPDH-OPe in cyclohexane $\left(3 \mu \mathrm{M}, \lambda_{\text {ex }}=410 \mathrm{~nm} ; \Phi_{\mathrm{f}}=41 \%\right.$ and $15 \%$ for $\mathrm{PPDH}$ and PPDH-OPe, respectively). For $\mathrm{NPDH}, \mathrm{R}=\mathrm{CH}\left(\mathrm{C}_{5} \mathrm{H}_{11}\right)_{2}$. however, the large increase in ECD from NPDH to PPDH in the 340-410 $\mathrm{nm}$ regime cannot be attributed to an increase in absorbance of unpolarized light. Relative to the Cotton effects of NPDH at 355 and $401 \mathrm{~nm}$, the Cotton effects of PPDH at 344 and $396 \mathrm{~nm}$ show a greater than threefold increase in $\Delta \varepsilon$. The same increases are not observed between the UV-visible absorbance spectra of these PDI-helicenes (Fig. 2b). In fact, the absorbance of NPDH and PPDH essentially match at 401 and $396 \mathrm{~nm}$, respectively, resulting in a significant disparity in $g$-factor $(|\Delta \varepsilon| / \varepsilon)$ at these wavelengths: $1.5 \times 10^{-3}$ for NPDH and $6.8 \times$ $10^{-3}$ for PPDH (Fig. 2c).

In addition to amplifying the ECD of PPDH compared to NPDH, the phenanthrene bridge also tunes photoluminescence. The pentoxy chains of PPDH-OPe lower the fluorescence quantum yield $\left(\Phi_{\mathrm{f}}\right)$ to $15 \%$, compared to $41 \%$ for unsubstituted PPDH. We attribute this decrease to intramolecular donor-acceptor charge transfer following excitation of the PDI-helicene. Excited-state charge transfer also accounts for fluorescence quenching in PDI-based compounds with $\pi$ donor substituents. ${ }^{48-50}$ On the other hand, the UV-visible and ECD spectra of PPDH and PPDH-OPe are nearly identical.

SCXRD revealed that the racemate of PPDH assembles into columns of alternating $M$ - and $P$-helices (Fig. 3 a and $\mathrm{S} 3 \dagger$ ). The intermolecular junction in these columns consists of 24 pairs of eclipsing $\pi$-bonded carbon atoms (see Fig. $\mathrm{S} 4 \uparrow$ for clarification),
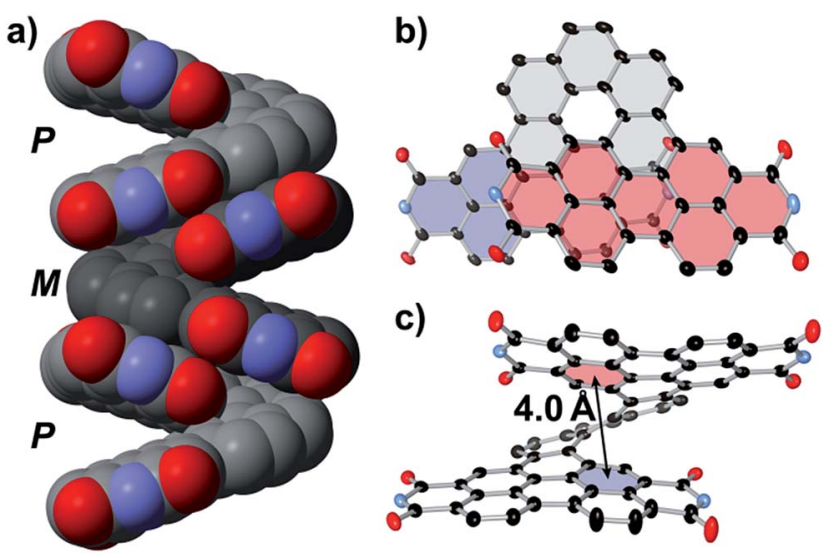

Fig. 3 Structure of PPDH from SCXRD. Free solvent, the $\mathrm{CH}\left(\mathrm{C}_{5} \mathrm{H}_{11}\right)_{2}$ chains, and hydrogen atoms have been hidden to provide an unobstructed view of the aryl surface. Thermal ellipsoids are set at 30\% probability. (a) The racemate assembles as heterochiral columns in the solid state. Extensive intramolecular overlap between the PDI subunits (b) distorts their perylene cores into shallow bowls (c). 
four of which approach to within $3.4 \AA$ (i.e., twice the van der Waals radius of the carbon atom). This heterochiral columnar packing arrangement resembles that observed previously for a $\pi$-helix-of-PDI-helicenes ${ }^{31}$ but differs from the crystal structures of other helical bilayer nanographenes. ${ }^{16,51}$ For these latter species, $\mathrm{C}-\mathrm{H} \cdots \pi$ interactions predominate, stymying intermolecular $\pi$-to- $\pi$ overlap. ${ }^{52}$

SCXRD also revealed extensive intramolecular overlap in PPDH (Fig. $3 b$ ); this contorts the $\pi$-surface. Each PDI subunit warps along its imide-to-imide axis, resulting in bend angles of $9^{\circ}$ and $11^{\circ}$ between the naphthalene fragments in each perylene (Fig. S5 $\dagger$ ). For reference, this angle in crystalline PDI-helicenes incorporating [5] and [6] helicene scaffolds measures $3^{\circ}$ and $6^{\circ}$, respectively. ${ }^{31,43}$ The [7] helicene scaffold in PPDH also splays farther from planarity than [7] helicene alone: the dihedral angle defined by the terminal rings of the [7]helicene within PPDH measures $40^{\circ}$, whereas the same angle in crystalline [7] helicene measures $32^{\circ} .^{53,54}$ Moreover, the centroid-to-centroid distance between these same rings in PPDH equals $4.0 \AA$ (Fig. 3c); the difference is $3.8 \AA$ in carbo[7]helicene. The resultant gap between the PDI-subunits can host guests: for instance, part of a molecule of $\alpha, \alpha, \alpha$-trifluorotoluene fills this $\pi$-cavity in the crystal structure of PPDH-OPe (Fig. S6†).

Cyclic voltammetry (CV) of PPDH in dichloromethane revealed three well-resolved reduction events (Fig. 4), all of which are chemically reversible. The two initial events $(-1.10$ and $-1.27 \mathrm{~V} v s . \mathrm{Fc} / \mathrm{Fc}^{+}$) are one electron processes, whereas the greater intensity of the third $\left(-1.54 v s\right.$. Fc/ $\left.\mathrm{Fc}^{+}\right)$affirms the nearsimultaneous addition of the third and fourth electrons; thus, PPDH accepts one electron per imide group. Similar three-event CV profiles have been observed for non-conjugated PDI-dimers with extensive intramolecular $\pi$-to- $\pi$ overlap $;^{55-57}$ therefore, one

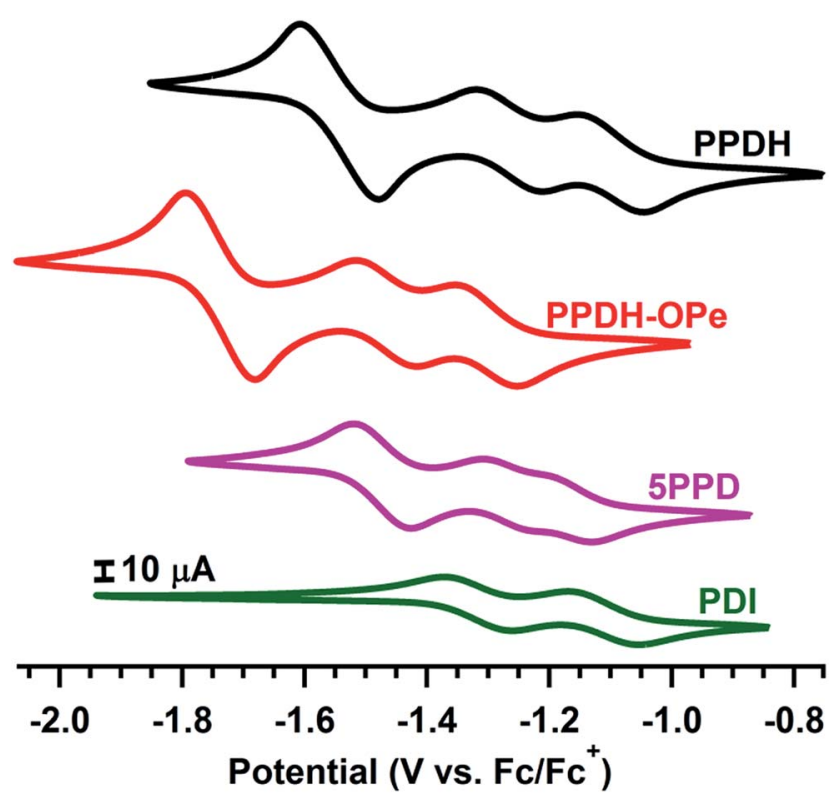

Fig. 4 Cyclic voltammograms of PPDH, PPDH-OPe, 5PPD, and monomeric PDI ( $1 \mathrm{mM}, 50 \mathrm{mV} \mathrm{s}^{-1}$ scan rate) in Ar-sparged DCM with $0.1 \mathrm{M}\left[\mathrm{Bu}_{4} \mathrm{~N}\right]\left[\mathrm{PF}_{6}\right]$ as the supporting electrolyte. For all species, $\mathrm{R}=$ $\mathrm{CH}\left(\mathrm{C}_{5} \mathrm{H}_{11}\right)_{2}$. might assume the fused phenanthrene linker in PPDH has a limited impact on the electrochemistry of the molecule. In fact, the bis(pentoxy)phenanthrene in PPDH-OPe cathodically shifts each reduction event by $200 \mathrm{mV}(-1.30,-1.47$, and $\left.-1.74 \mathrm{~V} v s . \mathrm{Fc} / \mathrm{Fc}^{+}\right)$. This LUMO elevation exceeds the $-180 \mathrm{mV}$ shift observed upon connecting two dodecoxy substituents directly to the bay regions of monomeric PDI. ${ }^{58}$ As such, the phenanthrene linker can be modified to significantly tune the onset of reduction in PPDH, without altering the overall electrochemical profile.

\section{Conclusions}

Visible-light-induced oxidative cyclization of phenanthryllinked PDI-dimer PPD yields the bilayer [7]helicene PPDH. Increasing the reaction temperature favors the near-exclusive formation of PPDH over its less strained isomers, 5PPD and PPPD. Intramolecular overlap of the $\pi$-surface of PPDH precludes racemization, even in solution at $250{ }^{\circ} \mathrm{C}$, and results in a voltammetric profile consistent with those of dimeric PDI molecules with similarly eclipsed surfaces. Substitutions onto the phenanthrene linker change the electrochemistry and some of the spectroscopic properties of PPDH. For instance, bis (pentoxy)phenanthrene quenches fluorescence and cathodically shifts the onset of reduction; however, it negligibly alters the UV-visible absorbance and ECD of PPDH. Racemic PPDH selfassembles into heterochiral columns in the solid state. The extensive intermolecular $\pi$-to- $\pi$ overlap within these columns could facilitate charge transport in organic electronic devices. Retention of the same crystalline morphology for optically pure PPDH would enable the preparation of transistors that respond preferentially to circularly polarized light, ${ }^{59}$ as well as potentially enhance chiral-induced spin selectivity. ${ }^{60}$

\section{Conflicts of interest}

There are no conflicts to declare.

\section{Acknowledgements}

C. N. thanks Sheldon and Dorothea Buckler for their generous support. Primary support for this project was provided by the U.S. Department of Energy (DOE) under award no. DESC0014563. Partial support was provided by the Office of Naval Research under award no. N00014-16-1-2921. Instruments in the Nakanishi and Owen laboratories at Columbia University were used for this research. We thank both laboratories, as well as Dr Nina Berova and Dr Steffen Jockusch, for their generosity. R. H. S. acknowledges the support from the Columbia Nano Initiative Postdoctoral Fellowship. SCXRD was performed at the Shared Materials Characterization Laboratory (SMCL) at Columbia University. Use of the SMCL was made possible by funding from Columbia University.

\section{Notes and references}

1 J. E. Anthony, Chem. Rev., 2006, 106, 5028-5048. 
2 V. Coropceanu, J. Cornil, D. A. da Silva Filho, Y. Olivier, R. Silbey and J.-L. Brédas, Chem. Rev., 2007, 107, 926-952.

3 C. Wang, H. Dong, W. Hu, Y. Liu and D. Zhu, Chem. Rev., 2012, 112, 2208-2267.

4 O. Ostroverkhova, Chem. Rev., 2016, 116, 13279-13412.

5 N. Berova, L. Di Bari and G. Pescitelli, Chem. Soc. Rev., 2007, 36, 914-931.

6 G. Pescitelli, L. Di Bari and N. Berova, Chem. Soc. Rev., 2011, 40, 4603-4625.

7 G. Pescitelli, L. Di Bari and N. Berova, Chem. Soc. Rev., 2014, 43, 5211-5233.

8 J. Kumar, T. Nakashima and T. Kawai, J. Phys. Chem. Lett., 2015, 6, 3445-3452.

9 E. M. Sánchez-Carnerero, A. R. Agarrabeitia, F. Moreno, B. L. Maroto, G. Muller, M. J. Ortiz and S. de la Moya, Chem.-Eur. J., 2015, 21, 13488-13500.

10 B. Gu, C. Zhao, A. Baev, K.-T. Yong, S. Wen and P. N. Prasad, Adv. Opt. Photonics, 2016, 8, 328-369.

11 D. Dini, M. J. F. Calvete and M. Hanack, Chem. Rev., 2016, 116, 13043-13233.

12 R. Naaman and D. H. Waldeck, J. Phys. Chem. Lett., 2012, 3, 2178-2187.

13 W. H. Laarhoven and W. J. C. Prinsen, Top. Curr. Chem., 1984, 125, 63-130.

14 Y. Shen and C.-F. Chen, Chem. Rev., 2012, 112, 1463-1535. 15 M. Gingras, Chem. Soc. Rev., 2013, 42, 968-1006.

16 P. J. Evans, J. Ouyang, L. Favereau, J. Crassous, I. Fernández, J. Perles and N. Martín, Angew. Chem., Int. Ed., 2018, 57, 6774-6779.

17 M. Scholz, M. Mühlstädt and F. Dietz, Tetrahedron Lett., 1967, 8, 665-668.

18 R. H. Martin, M. Flammang-Barbieux, J. P. Cosyn and M. Gelbcke, Tetrahedron Lett., 1968, 9, 3507-3510.

19 R. H. Martin, M.-J. Marchant and M. Baes, Helv. Chim. Acta, 1971, 54, 358-360.

20 F. B. Mallory and C. W. Mallory, J. Org. Chem., 1983, 48, 526-532.

21 A. Sudhakar and T. J. Katz, Tetrahedron Lett., 1986, 27, 22312234.

22 E. Murguly, R. McDonald and N. R. Branda, Org. Lett., 2000, 2, 3169-3172.

23 J. Roose, S. Achermann, O. Dumele and F. Diederich, Eur. J. Org. Chem., 2013, 3223-3231.

24 Y. Nakakuki, T. Hirose, H. Sotome, H. Miyasaka and K. Matsuda, J. Am. Chem. Soc., 2018, 140, 4317-4326.

25 K. Mori, T. Murase and M. Fujita, Angew. Chem., Int. Ed., 2015, 54, 6847-6851.

26 R. El Abed, B. Ben Hassine, J.-P. Genêt, M. Gorsane and A. Marinetti, Eur. J. Org. Chem., 2004, 1517-1522.

27 T. Kogiso, K. Yamamoto, H. Suemune and K. Usui, Org. Biomol. Chem., 2012, 10, 2934-2936.

28 W. H. Laarhoven, T. H. J. H. M. Cuppen and R. J. F. Nivard, Tetrahedron, 1970, 26, 4865-4881.

29 N. J. Schuster, D. W. Paley, S. Jockusch, F. Ng, M. L. Steigerwald and C. Nuckolls, Angew. Chem., Int. Ed., 2016, 55, 13519-13523.

30 K. Khokhlov, N. J. Schuster, F. Ng and C. Nuckolls, Org. Lett., 2018, 20, 1991-1994.
31 N. J. Schuster, R. Hernández Sánchez, D. Bukharina, N. A. Kotov, N. Berova, F. Ng, M. L. Steigerwald and C. Nuckolls, J. Am. Chem. Soc., 2018, 140, 6235-6239.

32 C. Lütke Eversloh, Z. Liu, B. Müller, M. Stangl, C. Li and K. Müllen, Org. Lett., 2011, 13, 5528-5531.

33 S. Xiao, S. J. Kang, Y. Wu, S. Ahn, J. B. Kim, Y.-L. Loo, T. Siegrist, M. L. Steigerwald, H. Li and C. Nuckolls, Chem. Sci., 2013, 4, 2018-2023.

34 T. Fujikawa, Y. Segawa and K. Itami, J. Am. Chem. Soc., 2015, 137, 7763-7768.

35 T. Fujikawa, Y. Segawa and K. Itami, J. Org. Chem., 2017, 82, 7745-7749.

36 Y. Hu, X.-Y. Wang, P.-X. Peng, X.-C. Wang, X.-Y. Cao, X. Feng, K. Müllen and A. Narita, Angew. Chem., Int. Ed., 2017, 56, 3374-3378.

37 C. M. Cruz, I. R. Márquez, I. F. A. Mariz, V. Blanco, C. Sánchez-Sánchez, J. M. Sobrado, J. A. Martín-Gago, J. M. Cuerva, E. Maçôas and A. G. Campaña, Chem. Sci., 2018, 9, 3917-3924.

38 D. Reger, P. Haines, F. W. Heinemann, D. M. Guldi and N. Jux, Angew. Chem., Int. Ed., 2018, 57, 5938-5942.

39 Y. Zhu, Z. Xia, Z. Cai, Z. Yuan, N. Jiang, T. Li, Y. Wang, X. Guo, Z. Li, S. Ma, D. Zhong, Y. Li and J. Wang, J. Am. Chem. Soc., 2018, 140, 4222-4226.

40 K. Kato, Y. Segawa, L. T. Scott and K. Itami, Angew. Chem., Int. Ed., 2018, 57, 1337-1341.

41 C. M. Cruz, S. Castro-Fernández, E. Maçôas, J. M. Cuerva and A. G. Campaña, Angew. Chem., Int. Ed., 2018, 57, 1478214786.

42 P. E. Hartnett, H. S. S. R. Matte, N. D. Eastham, N. E. Jackson, Y. Wu, L. X. Chen, M. A. Ratner, R. P. H. Chang, M. C. Hersam, M. R. Wasielewski and T. J. Marks, Chem. Sci., 2016, 7, 3543-3555.

43 D. Meng, H. Fu, C. Xiao, X. Meng, T. Winands, W. Ma, W. Wei, B. Fan, L. Huo, N. L. Doltsinis, Y. Li, Y. Sun and Z. Wang, J. Am. Chem. Soc., 2016, 138, 10184-10190.

44 Y. Li, L. Xu, T. Liu, Y. Yu, H. Liu, Y. Li and D. Zhu, Org. Lett., 2011, 13, 5692-5695.

45 R. H. Martin and M. J. Marchant, Tetrahedron, 1974, 30, 347349.

46 Y. Nakai, T. Mori and Y. Inoue, J. Phys. Chem. A, 2012, 116, 7372-7385.

47 For example: C. Schaack, E. Sidler, N. Trapp and F. Diederich, Chem.-Eur. J., 2017, 23, 14153-14157.

48 F. Würthner, C. Thalacker, S. Diele and C. Tschierske, Chem.-Eur. J., 2001, 7, 2245-2253.

49 Á. J. Jiménez, F. Spänig, M. S. Rodríguez-Morgade, K. Ohkubo, S. Fukuzumi, D. M. Guldi and T. Torres, Org. Lett., 2007, 9, 2481-2484.

50 C. Huang, S. Barlow and S. R. Marder, J. Org. Chem., 2011, 76, 2386-2407.

51 M. Buchta, J. Rybáček, A. Jančařík, A. A. Kudale, M. Buděšínský, J. V. Chocholoušová, J. Vacek, L. Bednárová, I. Císařová, G. J. Bodwell, I. Starý and I. G. Stará, Chem.-Eur. J., 2015, 21, 8910-8917.

52 C. A. Hunter and J. K. M. Sanders, J. Am. Chem. Soc., 1990, 112, 5525-5534. 
53 M. J. Fuchter, M. Weimar, X. Yang, D. K. Judge and A. J. P. White, Tetrahedron Lett., 2012, 53, 1108-1111.

54 S. Fujino, M. Yamaji, H. Okamoto, T. Mutai, I. Yoshikawa, H. Houjou and F. Tani, Photochem. Photobiol. Sci., 2017, 16, 925-934.

55 J. Feng, Y. Zhang, C. Zhao, R. Li, W. Xu, X. Li and J. Jiang, Chem.-Eur. J., 2008, 14, 7000-7010.

56 F. Schlosser, M. Moos, C. Lambert and F. Würthner, Adv. Mater., 2013, 25, 410-414.
57 K. M. Lefler, K. E. Brown, W. A. Salamant, S. M. Dyar, K. E. Knowles and M. R. Wasielewski, J. Phys. Chem. A, 2013, 117, 10333-10345.

58 C. Zhao, Y. Zhang, R. Li, X. Li and J. Jiang, J. Org. Chem., 2007, 72, 2402-2410.

59 Y. Yang, R. Correa Da Costa, M. J. Fuchter and A. J. Campbell, Nat. Photonics, 2013, 7, 634-638.

60 V. Kiran, S. P. Mathew, S. R. Cohen, I. Hernández Delgado, J. Lacour and R. Naaman, Adv. Mater., 2016, 28, 1957-1962. 